Buletin Ilmiah Math. Stat. dan Terapannya (Bimaster)

Volume 08, No. 4 (2019), hal 875 - 882.

\title{
PREDIKSI PRODUKSI KELAPA SAWIT DI PTPN XIII DENGAN ADDITIVE OUTLIER PADA MODEL SEASONAL AUTOREGRESSIVE INTEGRATED MOVING AVERAGE (SARIMA)
}

\author{
Nada Syaugia Risti Ahmad, Shantika Martha, Nurfitri Imro'ah \\ INTISARI
}

\begin{abstract}
Model SARIMA adalah model yang sesuai untuk data yang memiliki pola musiman. Dalam data biasanya terdapat outlier yang dapat mempengaruhi kesesuaian model sehingga dilakukan deteksi outlier pada model SARIMA untuk mendapatkan model peramalan yang terbaik. Salah satu jenis outlier yaitu additive outlier (AO). Data yang digunakan dalam penelitian ini merupakan data produksi kelapa sawit periode Januari 2010 sampai Desember 2017. Data produksi kelapa sawit di Kalimantan Barat memiliki pola data musiman dan diduga memiliki outlier pada data maka dilakukan pemodelan dan peramalan dengan menggunakan additive outlier pada model SARIMA. Berdasarkan analisis diperoleh bahwa nilai AIC pada model SARIMA adalah sebesar 2.070,72 dan nilai MAPE nya sebesar 25\% sedangkan model SARIMA dengan deteksi outlier diperoleh nilai AIC sebesar 1.731,42 dan nilai MAPE sebesar 15,91\%. Maka dapat disimpulkan bahwa model SARIMA dengan deteksi outlier adalah model terbaik untuk peramalan produksi kelapa sawit di PTPN XIII.
\end{abstract}

Kata Kunci: Kelapa sawit, peramalan, SARIMA, outlier

\section{PENDAHULUAN}

Salah satu perusahaan perkebunan kelapa sawit yang ada di Kalimantan adalah PT. Perkebunan Nusantara XIII yang selanjutnya dikenal PTPN XIII. PTPN XIII merupakan Badan Usaha Milik Negara (BUMN) perkebunan di wilayah Kalimantan. PTPN XIII memiliki luas areal kebun kelapa sawit sebesar 113.348 Ha yang terdiri dari kebun sendiri sebesar 55.440 Ha dan kebun plasma sebesar 57.908 Ha. Unit kerja PTPN XIII dibagi menjadi dua distrik, yaitu Distrik Kalimantan Barat I dan Distrik Kalimantan Barat II dimana kedua unit kerja tesebut tersebar di Kabupaten Landak, Kabupaten Sanggau dan Kabupaten Sintang [1].

Masalah yang dihadapi oleh perusahaan bidang kelapa sawit adalah munculnya biaya yang tidak terduga seperti biaya transportasi dan biaya penyimpanan gudang untuk pasokan tandan buah segar (TBS). Salah satu cara untuk mengantisipasi hal ini adalah dengan meramalkan jumlah pasokan TBS. Dengan melakukan peramalan pada pasokan TBS, perusahaan dapat mengetahui instrumen-instrumen dan biaya yang diperlukan seperti jumlah armada yang mengangkut TBS, jumlah box atau gudang yang diperlukan.

Peramalan merupakan suatu upaya memprediksi nilai dari suatu variabel berdasarkan nilai yang diketahui dari variabel tersebut pada masa lalu atau variabel yang berhubungan. Metode deret waktu pendugaan masa depan dilakukan berdasarkan nilai masa lalu dari satu variabel [2]. Salah satu model pada metode deret waktu yang dapat digunakan untuk memprediksi adalah model Seasonal Autoregressive Integrated Moving Average (SARIMA). SARIMA merupakan pengembangan dari model Autoregressive Integrated Moving Average (ARIMA) pada data deret waktu yang memiliki pola musiman. Dalam pengamatan-pengamatan yang ada, data deret waktu seringkali dipengaruhi oleh kejadian-kejadian yang tidak terduga sebelumnya. Kejadian-kejadian ini biasanya menghasilkan serangkaian kejadian yang tidak konsisten. Kejadian yang tidak konsisten inilah yang dinamakan dengan pencilan (outlier). 
Penelitian ini bertujuan melakukan pemodelan dan peramalan produksi kelapa sawit PTPN XIII pada tahun 2018 dengan menggunakan additive outlier pada model SARIMA. Langkah pertama dalam analisis adalah pengumpulan data jumlah produksi kelapa sawit di PT. Perkebunan Nusantara XIII. Data yang diperoleh dibuat plot untuk melihat pola data. Setelah mengetahui pola data, maka dilakukan uji kestasioneran. Jika data tidak stasioner terhadap varians maka dilakukan transformasi data dan diuji kembali kestasionerannya. Data yang telah stasioner, selanjutnya dilakukan identifikasi model untuk menentukan ordo model SARIMA dengan melihat plot ACF dan PACF.

Selanjutnya hasil estimasi parameter dilakukan untuk mengetahui signifikansi parameter. Langkah selanjutnya, melakukan pengujian diagnostik yaitu uji white noise, uji homoskedastisitas dan uji normalitas pada model yang telah didapat untuk mengetahui apakah model dapat dikatakan baik untuk proses peramalan. Setelah diperoleh model SARIMA terbaik maka dilakukan pendeteksian outlier untuk mengetahui jenis outlier yang terdapat pada data. Setelah mengetahui jenis outlier maka dilakukan penambahan model outlier satu persatu pada model SARIMA.

Selanjutnya dilakukan identifikasi dan estimasi parameter model dengan outlier untuk mengetahui apakah model signifikan. Setelah mendapat model SARIMA dengan outlier maka nilai Aikake Information Criterion (AIC) dibandingkan dengan nilai AIC model SARIMA tanpa outlier untuk mengetahui model terbaik. Selanjutnya dilakukan peramalan dengan menggunakan model terbaik untuk meramalkan jumlah produksi kelapa sawit pada tahun 2018, dan menentukan nilai Mean Absolute Percentage Error (MAPE) untuk mengetahui kriteria hasil peramalan.

\section{ANALISIS DERET WAKTU}

Data deret waktu merupakan data yang dikumpulkan dari waktu ke waktu untuk menggambarkan perkembangan dari suatu kegiatan. Apabila deret waktu data digambarkan oleh suatu diagram maka akan memperlihatkan suatu fluktuasi, yang merupakan gerakan naik turun dan dapat digunakan sebagai dasar penarikan trend atau garis yang menunjukan arah perkembangan dari suatu data. Data deret waktu sangat diperlukan oleh suatu organisasi karena dapat melihat perkembangan dan sebagai alat kontrol dalam beberapa bidang seperti keuangan, produksi penjualan dan lain sebagainya.

Kestasioneran data dalam rata-rata dapat diuji menggunakan ADF dengan model sebagai berikut [3]:

$$
Z_{t}=a+\phi Z_{t-1}+a_{t}
$$

Hipotesis yang di uji adalah sebagai berikut [3]:

$H_{0}$ : Data tidak stasioner

$H_{1}$ : Data stasioner

Uji tersebut diketahui sebagai uji akar-akar unit dengan statistik uji [3]:

$$
A D F_{\text {hitung }}=\frac{\hat{\phi}}{S E(\hat{\phi})}
$$

Dengan $S E \hat{\phi}=\left[\frac{\sigma^{2}}{\sum_{t=1}^{n}\left(Z_{t-1}-\bar{Z}_{t-1}\right)^{2}}\right]^{\frac{1}{2}}$ dan $\hat{\sigma}^{2}=\frac{\sum_{t=1}^{n} \hat{e}_{t}^{2}}{n-m}$ dimana $n$ adalah jumlah pengamatan dan

$m$ adalah jumlah parameter yang diestimasi. Data dikatakan stasioner jika nilai mutlak ADF hitung lebih dari nilai kritis $\mathrm{ADF}$ atau nilai probabilitas $\mathrm{ADF}$ kurang dari tingkat signifikansi yang ditentukan.

Dalam pemodelan deret waktu sering juga ditemukan data dengan kondisi tidak stasioner dalam variansi. Untuk menstasionerkan data yang tidak stasioner dalam variansi dapat dilakukan dengan transformasi data sehingga didapatkan data yang stasioner dalam variansi. Salah satu transformasi 
yang dapat digunakan adalah transformasi Box-Cox. Transformasi Box-Cox adalah transformasi pangkat pada respon dengan bentuk transformasi sebagai berikut [4]:

$$
T\left[Z_{t}\right]=Z_{t}^{(\lambda)}=\left\{\begin{array}{c}
\frac{Z_{t}^{(\lambda)}-1}{\lambda}, \lambda \neq 0 \\
\ln Z_{t}, \lambda=0
\end{array}\right.
$$

dimana $\lambda$ merupakan parameter transformasi.

\section{MODEL SEASONAL AUTOREGRESSIVE MOVING AVERAGE (SARIMA)}

Model SARIMA merupakan pengembangan dari model Autoregressive Integrated Moving Average (ARIMA) pada data deret waktu yang memiliki pola musiman. Generalisasi dari model ARIMA untuk data yang memiliki pola musiman, yaitu $\operatorname{SARIMA}(p, d, q)(P, D, Q)^{S}$ dirumuskan sebagai berikut [4]:

dengan,

$$
\phi_{p}(B) \Phi_{p}\left(B^{S}\right)(1-B)^{d}\left(1-B^{S}\right)^{D} X_{t}=\theta_{q}(B) \Theta_{Q}\left(B^{S}\right) a_{t}
$$

$p, d, q \quad$ : ordo AR, differencing, MA non musiman

$P, D, Q \quad$ : ordo AR, differencing, MA musiman

$S \quad$ : Musiman

$\Phi_{p}\left(B^{S}\right) \quad:$ koefisien komponen AR musiman $S$ dengan ordo $P\left(1-\Phi_{1} B^{S}-\cdots-\Phi_{p} B^{S}\right)$

$\Theta_{Q}\left(B^{S}\right) \quad$ : koefisien komponen MA musiman $S$ dengan ordo $Q\left(1-\Theta_{1} B^{S}-\cdots-\Theta_{Q} B^{S}\right)$

$\left(1-B^{S}\right)^{D} \quad$ : differencing musiman $S$ dengan ordo $D$

$a_{t} \quad$ : Nilai error pada waktu ke-t.

\section{ADDITIVE OUTLIER}

Additive outlier (AO) adalah kejadian yang mempunyai efek pada data time series hanya pada satu periode saja yaitu pada pengamatan ke-T. Bentuk umum sebuah AO didefinisikan sebagai berikut [4]:

$$
Z_{t}=\left\{\begin{array}{cc}
X_{t} & t \neq T \\
X_{t}+\omega & t=T
\end{array}\right.
$$

misalkan $I_{t}^{(T)}=\left\{\begin{array}{ll}1 & t=T \\ 0 & t \neq T\end{array}\right.$ maka $Z_{t}$ dapat dituliskan sebagai berikut:

$$
\begin{aligned}
Z_{t} & =X_{t}+\omega I_{t}^{(T)} \\
& =\frac{\theta_{q}(B) \Theta_{Q}\left(B^{S}\right)}{\phi_{p}(B) \Phi_{p}\left(B^{S}\right)(1-B)^{d}\left(1-B^{S}\right)^{D}} a_{t}+\omega I_{t}^{(T)}
\end{aligned}
$$

dimana $I_{t}^{(T)}$ dalah variabel indikator yang mewakili ada atau tidak adanya outlier pada waktu T.

\section{IDENTIFIKASI DATA}

Data yang digunakan pada penelitian ini adalah data produksi kelapa sawit (ton) pada PTPN XIII. Ukuran sampel yang digunakan dalam penelitian ini adalah 96 sampel. Data tersebut merupakan data bulanan produksi dari bulan Januari 2010 sampai dengan Desember 2017. Berdasarkan Gambar 1 terlihat bahwa dalam data produksi kelapa sawit di Kalimantan Barat memiliki pola deret waktu musiman. Produksi kelapa sawit tiap tahun cenderung memiliki peningkatan yang signifikan pada akhir tahun, sehingga memiliki kemungkinan bahwa terdapat outlier pada data tersebut. 


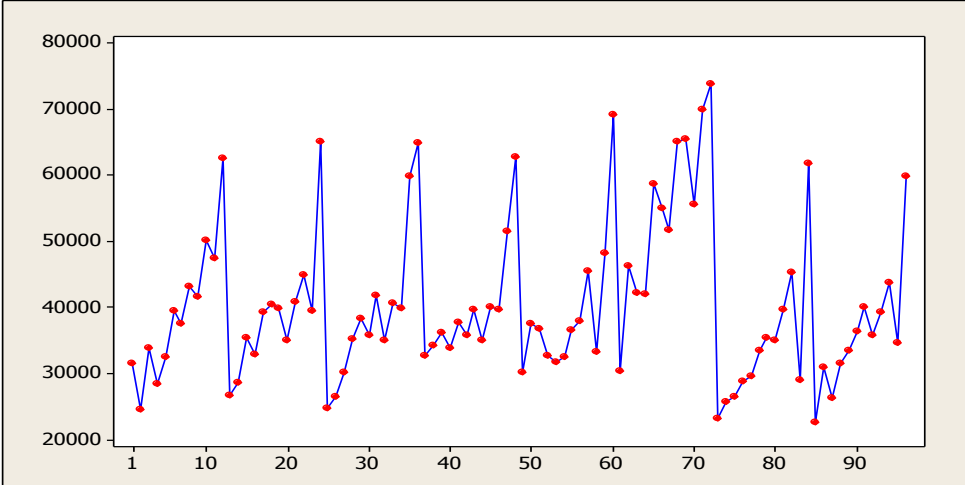

Gambar 1 Plot deret waktu Produksi Kelapa Sawit pada Januari 2010 sampai dengan Desember 2017

Untuk memeriksa apakah data stasioner dalam variansi dapat menggunakan transformasi Box-Cox.

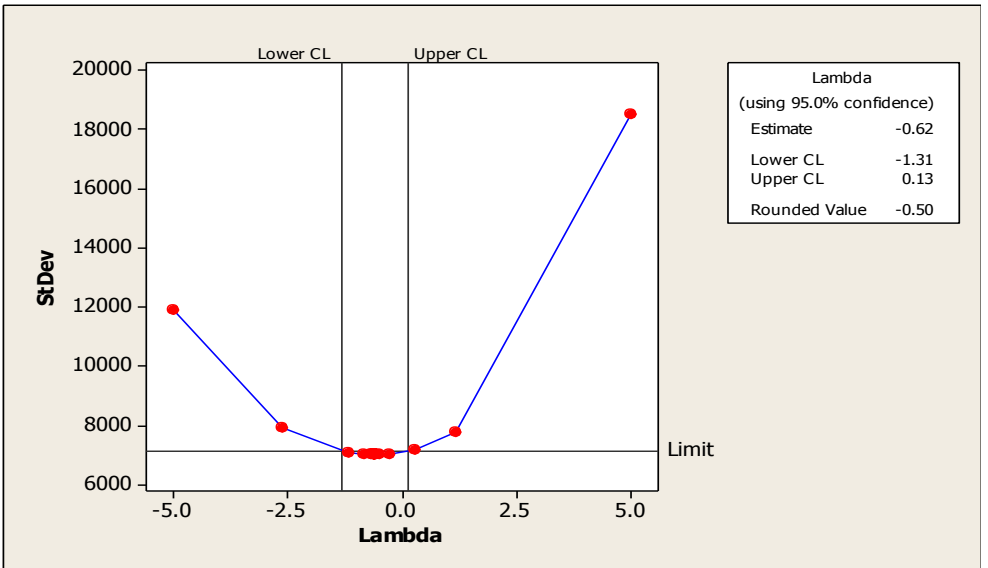

Gambar 2 Plot Box-Cox Produksi Kelapa Sawit

Gambar 2 menunjukkan hasil uji Box-Cox terlihat bahwa nilai rounded value $(\lambda)=-0,50$ sehingga data dikatakan belum stasioner terhadap varians. Sehingga data perlu ditransformasi agar nilai $\lambda$ menjadi optimum yaitu bernilai satu, maka transformasi yang tepat dengan nilai $\lambda=-0,50$ adalah $\frac{1}{\sqrt{z_{t}}}[4]$.

Setelah dilakukan transformasi pada data, maka diperoleh hasil pada Gambar 3.

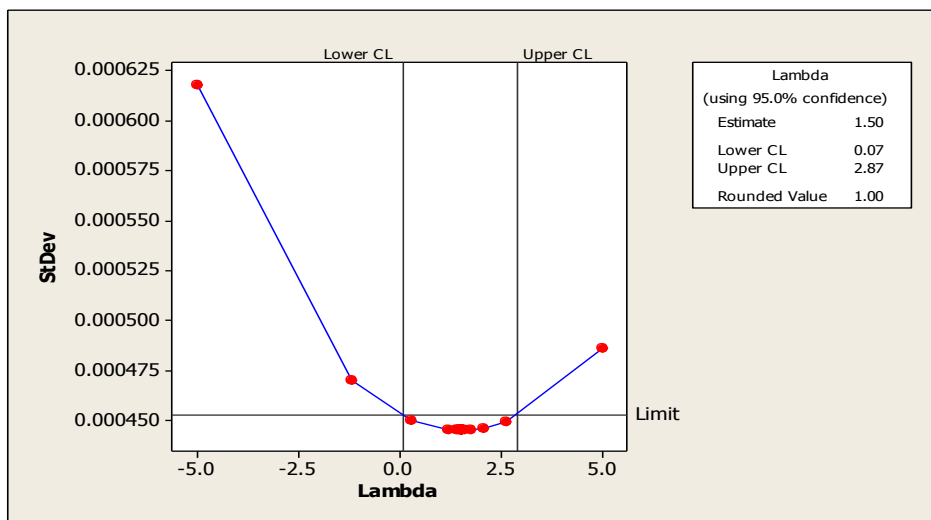

\section{Gambar 3 Plot Box-Cox Produksi Kelapa Sawit Transformasi Pertama}

Gambar 3 menunjukkan transformasi hasil uji Box-Cox terlihat bahwa nilai $\lambda$ adalah 1,00 sehingga data sudah stasioner dalam varian. Sehingga dapat disimpulkan bahwa data produksi kelapa sawit 
yang telah ditransformasi sudah stasioner dalam varian. Data yang telah diuji ke stasionerannya terhadap varians selanjutnya diuji kembali kestasionerannya terhadap rata-rata dengan menggunakan uji Augmented Dickey-Fuller (ADF), maka diperoleh hasil pada Tabel 1.

Tabel 1 Hasil Uji ADF pada Data Produksi Kelapa Sawit

\begin{tabular}{lrrr}
\hline & t-Statistic & Prob.* \\
\hline $\begin{array}{l}\text { Augmented Dickey-Fuller test } \\
\text { statistic }\end{array}$ & $-6,715$ & 0,000 \\
\hline Test critical & & & \\
values: & $1 \%$ level & $-3,500$ & \\
& $5 \%$ level & $-2,892$ & \\
& $10 \%$ level & $-2,583$ & \\
\hline
\end{tabular}

Berdasarkan Tabel 1 dapat diketahui bahwa nilai Prob.* kurang dari $\alpha(0,05)$ maka hasil uji (ADF) menunjukan bahwa data produksi kelapa sawit di Kalimantan Barat stasioner sehingga tidak perlu dilakukan differencing.

\section{IDENTIFIKASI MODEL SARIMA}

Setelah asumsi kestasioneran data terpenuhi, maka selanjutnya dapat menduga model ARIMA dengan melihat plot ACF untuk mengetahui orde MA dan PACF untuk mengetahui orde AR. Plot ACF dan PACF disajikan pada Gambar 4 dan Gambar 5:

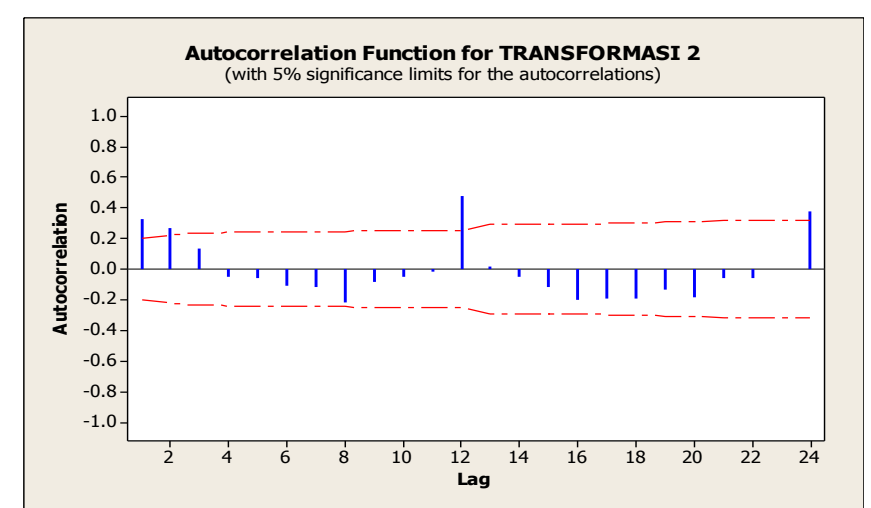

Gambar 4 Plot ACF Data Produksi Kelapa Sawit

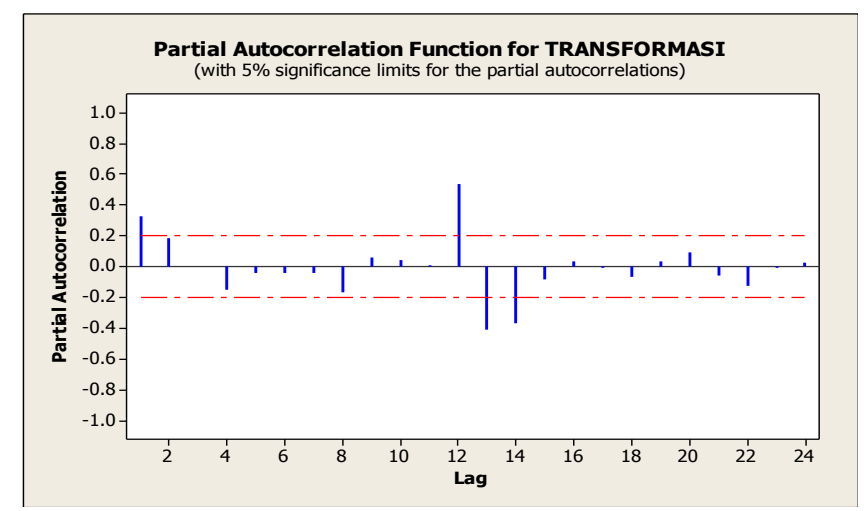

Gambar 5 Plot PACF Data Produksi Kelapa Sawit

Pemodelan SARIMA untuk data produksi kelapa sawit dapat dilihat berdasarkan plot ACF pada Gambar 4 dimana lag yang terpotong adalah lag pertama dan kedua sedangkan plot PACF pada Gambar 5 dimana lag terpotong adalah lag pertama sehingga diperoleh model-model sementara. 
Setelah diperoleh dugaan model sementara, maka tahap berikutnya adalah melakukan estimasi model. Selanjutnya, dilakukan uji diagnostik yaitu uji white noise untuk memeriksa apakah residual berkorelasi atau tidak, uji homoskedastisitas untuk memeriksa apakah ada residual yang tidak konstan dan uji normalitas untuk memeriksa apakah residual berdistribusi normal. Dari estimasi parameter model dan uji diagnostik yang telah dilakukan maka diperoleh model terbaik hasil overfitting seperti terlihat pada Tabel 2.

Tabel 2 Pemodelan Terbaik Hasil Overfitting

\begin{tabular}{|c|c|c|c|c|c|}
\hline Model SARIMA & $\begin{array}{l}\text { Signifikansi } \\
\text { Parameter }\end{array}$ & White noise & Homoskedastisitas & Normalitas & AIC \\
\hline$(1,0,0)(1,0,0)^{12}$ & $\begin{array}{l}\operatorname{AR}(1)=-0,46 \\
\operatorname{SAR}(1)=0,99\end{array}$ & Terpenuhi & Terpenuhi & $\begin{array}{r}\text { Tidak } \\
\text { Terpenuhi }\end{array}$ & $2.173,54$ \\
\hline$(1,0,1)(1,0,0)^{12}$ & $\begin{array}{r}\operatorname{AR}(1)=0,34 \\
\operatorname{SAR}(1)=1,00 \\
\operatorname{MA}(1)=-0,99\end{array}$ & Terpenuhi & Terpenuhi & $\begin{array}{r}\text { Tidak } \\
\text { Terpenuhi }\end{array}$ & $2.161,83$ \\
\hline$(1,0,1)(0,0,2)^{12}$ & $\begin{array}{r}\mathrm{AR}(1)=1,00 \\
\mathrm{MA}(1)=-0.99 \\
\mathrm{SMA}(2)=0.32 \\
\end{array}$ & Terpenuhi & Terpenuhi & Terpenuhi & $2.070,72$ \\
\hline$(1,0,1)(1,0,1)^{12}$ & $\begin{array}{r}\operatorname{AR}(1)=-0,68 \\
\operatorname{SAR}(1)=0,99 \\
\operatorname{MA}(1)=-0,63 \\
\operatorname{SMA}(1)=0,70\end{array}$ & Terpenuhi & $\begin{array}{r}\text { Tidak } \\
\text { Terpenuhi }\end{array}$ & $\begin{array}{r}\text { Tidak } \\
\text { Terpenuhi }\end{array}$ & $2.161,60$ \\
\hline
\end{tabular}

Pada Tabel 2 terlihat bahwa model SARIMA terbaik yaitu model SARIMA $(1,0,1)(0,0,2)^{12}$ dengan nilai AIC sebesar 2.070,72. Model SARIMA produksi kelapa sawit adalah:

$$
Z_{t}=(1-0,99 B)\left(1-0,32 B^{24}\right) a_{t}+Z_{t-1}
$$

\section{DETEKSI OUTLIER}

Untuk mengetahui ada atau tidaknya outlier dalam data, maka dilakukan deteksi outlier. Dari Tabel 3 terlihat bahwa terdeteksi lima outlier yang bertipe Additive Outlier (AO) dan dilakukan pemilihan model terbaik yang dilihat dari nilai AIC terkecil dari model.

\begin{tabular}{lc}
\multicolumn{2}{c}{ Tabel 3 Perbandingan AIC Model Dengan Outlier } \\
\hline \multicolumn{2}{c}{ SARIMA $(1,0,1)(0,0,2)^{12}$} \\
\multicolumn{2}{c}{ dengan Penambahan model outlier } \\
\hline 24 & AIC \\
24,84 & $1.741,38$ \\
$24,84,60$ & $1.738,36$ \\
$24,84,60,48$ & $1.737,62$ \\
$24,84,60,48,96$ & $1.735,60$ \\
\hline
\end{tabular}

Berdasarkan Tabel 3 diperoleh model terbaik adalah SARIMA $(1,0,1)(0,0,2)^{12}$ dengan deteksi outlier karena memiliki nilai AIC yang lebih kecil dibandingkan model yang lain yaitu sebesar 1.731,42. Jadi model yang terbentuk untuk data produksi kelapa sawit adalah sebagai berikut:

$$
\begin{gathered}
Z_{t}=(1-0,997460 B)\left(1-0,323681 B^{24}\right) a_{t}+Z_{t-1}+22.902,1 I_{t}^{(24)}+22.419,4 I_{t}^{(84)} \\
+20.286,2 I_{t}^{(60)}+18.983,5 I_{t}^{(48)}+19.701,1 I_{t}^{(96)}
\end{gathered}
$$


Perbandingkan model SARIMA $(1,0,1)(0,0,2)^{12}$ dengan deteksi outlier dan tanpa deteksi outlier terlihat pada Tabel 4 bahwa nilai AIC model dengan deteksi outlier lebih kecil dibandingkan dengan model tanpa deteksi outlier.

Tabel 4 Perbandingan AIC Model Dengan deteksi Outlier dan Tanpa deteksi Outlier

\begin{tabular}{lc}
\hline \multicolumn{1}{c}{ Model } & AIC \\
\hline SARIMA $(1,0,1)(0,0,2)^{12}$ & $2.070,72$ \\
\hline SARIMA $(1,0,1)(0,0,2)^{12}$ dengan deteksi outlier & $\mathbf{1 . 7 3 1 , 4 2}$ \\
\hline
\end{tabular}

\section{PERAMALAN PRODUKSI KELAPA SAWIT}

Setelah mendapatkan model terbaik, langkah selanjutnya adalah melakukan peramalan pada dataproduksi kelapa sawit. Hasil peramalan produksi kelapa sawit disajikan pada Tabel 5.

\begin{tabular}{lrrr}
\multicolumn{3}{c}{ Tabel 5 Data Aktual dan Hasil Peramalan Produksi Kelapa Sawit. } \\
\hline Bulan & Data Aktual & SARIMA & $\begin{array}{c}\text { SARIMA dengan } \\
\text { Deteksi outlier }\end{array}$ \\
\hline Januari & 33.378 & $63.608,64$ & $32.358,12$ \\
Februari & 28.802 & $32.718,55$ & $42.119,37$ \\
Maret & 29.297 & $22.796,23$ & $32.208,28$ \\
April & 31.224 & $28.776,22$ & $33.715,30$ \\
Mei & 36.556 & $27.106,87$ & $33.898,52$ \\
Juni & 30.639 & $42.681,95$ & $34.600,80$ \\
Juli & 30.300 & $39.081,13$ & $34.814,32$ \\
Agustus & 36.790 & $38.049,59$ & $33.640,36$ \\
September & 42.010 & $35.275,04$ & $31.349,80$ \\
Oktober & 43.993 & $44.181,60$ & $36.804,45$ \\
November & 43.053 & $36.012,41$ & $30.226,61$ \\
Desember & 62.189 & $38.616,58$ & $67.500,06$ \\
\hline MAPE & & $25 \%$ & $\mathbf{1 5 , 9 1 \%}$ \\
\hline
\end{tabular}

Hasil peramalan produksi kelapa sawit selanjutnya di evaluasi dengan menggunakan MAPE untuk mengetahui keakuratan hasil peramalan. Nilai MAPE yang diperoleh adalah sebesar 15,91\% yang artinya proses peramalan jumlah produksi kelapa sawit periode Januari 2018 sampai dengan Desember 2018 dengan menggunakan model SARIMA $(1,0,1)(0,0,2)^{12}$ dengan deteksi outlier dinilai baik. Hal ini juga dapat dilihat secara visual pada Gambar 5.

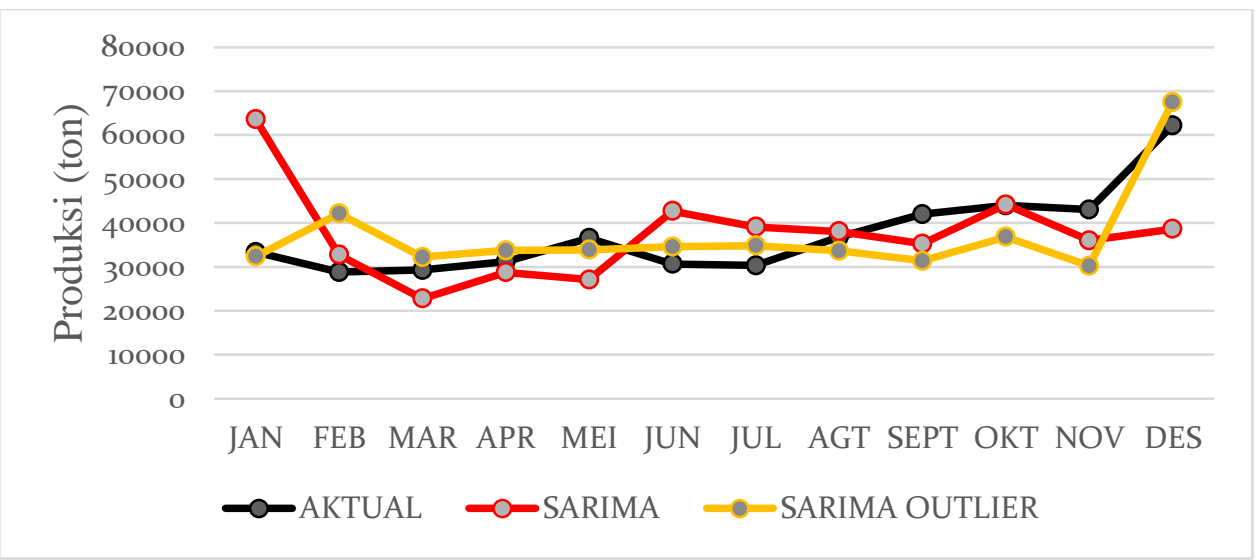

Gambar 5 Perbandingan Data Aktual dan Hasil Peramalan Tahun 2018 


\section{KESIMPULAN}

1. Berdasarkan hasil pembahasan diperoleh model SARIMA terbaik untuk meramalkan produksi kelapa sawit yaitu model SARIMA $(1,0,1)(0,0,2)^{12}$. Bentuk persamaan dari model yaitu:

$$
Z_{t}=(1-0,99)\left(1-0,32 B^{24}\right) a_{t}+Z_{t-1} \text {. }
$$

Dari hasil pembahasan juga diperoleh model SARIMA $(1,0,1)(0,0,2)^{12}$ dengan deteksi outlier yaitu:

$$
\begin{aligned}
Z_{t}= & (1-0,99 B)\left(1-0,32 B^{24}\right) a_{t}+Z_{t-1}+22.902,10 I_{t}^{(24)} \\
& +22.419,40 I_{t}^{(84)}+20.286,20 I_{t}^{(60)}+18.983,50 I_{t}^{(48)}+19.701,10 I_{t}^{(96)}
\end{aligned}
$$

dan diperoleh bahwa model SARIMA dengan deteksi outlier adalah model terbaik untuk meramalkan jumlah produksi kelapa sawit.

2. Dari model SARIMA $(1,0,1)(0,0,2)^{12}$ dengan deteksi outlier diperoleh hasil peramalan produksi kelapa sawit untuk periode 12 bulan kedepan dengan nilai MAPE sebesar 15,91\% sehingga hasil peramalan dapat dikatakan baik.

\section{DAFTAR PUSTAKA}

[1]. PTPN 13. Sejarah PT. Perkebunan Nusantara XIII. (online), www.ptpn13.com. (12 Juli 2019);2012.

[2]. Makridakis, S., Wheelwright, S. C., dan McGee, V. E. Metode dan Aplikasi Peramalan. Jakarta: Bina Rupa Aksara;1999.

[3]. Gujarati, D.N. Basic Econometrics Edisi keempat. New York: Mc-Graw Hill;2003

[4]. Wei, W. W. S. Time Series Analysis: Univariate and Multivariate Methods Second Edition. New York: Addison Wesley;2006.

NADA SYAUGIA RISTI AHMAD

SHANTIKA MARTHA

NURFITRI IMRO'AH
: Jurusan Matematika FMIPA UNTAN, Pontianak nada.syaugia98@gmail.com

: Jurusan Matematika FMIPA UNTAN, Pontianak shantika.martha@math.untan.ac.id

: Jurusan Matematika FMIPA UNTAN, Pontianak nurfitriimroah@math.untan.ac.id 